УДК 537.62

\title{
On the Hierarchy of the Characteristic Lengths of Nanowires Magnetization
}

\author{
Anatoly A. Ivanov* \\ Institute of Non-Ferrous Metals and Material Science \\ Siberian Federal University \\ Svobodny, 79, Krasnoyarsk, 660041 \\ Russia \\ Vitaly A. Orlov ${ }^{\dagger}$ \\ Institute of Engineering Physics and Radio Electronics \\ Siberian Federal University \\ Svobodny, 79, Krasnoyarsk, 660041 \\ Krasnoyarsk Science Centre SB RAS \\ Akademgorodok 50, Krasnoyarsk, 660036
}

Russia

Received 20.08.2016, received in revised form 10.10.2016, accepted 14.11.2016

Using computer simulation of magnetization in a polycrystalline ferromagnetic nanowire, we demonstrate the occurrence of the characteristic spatial scale in the distribution of magnetization unrelated to the domain wall or crystallite size. This is the stochastic domain size. We show that this length not only manifests itself in the analysis of magnetization distribution but is included in the spectral density of the force pinning a domain wall to inhomogeneities of the crystallographic anisotropy. The parameters of a stochastic domain, including the constant and distribution of axes directions of the effective anisotropy, are analytically calculated.

Keywords: domain wall, nanowire, magnetic inhomogeneities.

DOI: 10.17516/1997-1397-2017-10-1-60-64.

In this work, we investigate the unusual self-organization type, specifically, the occurrence of the stochastic magnetization superstructure in a polycrystalline $1 \mathrm{D}$ ferromagnet. A polycrystalline nanowire with a crystallite size somewhat smaller than the domain wall thickness (tens of nanometers) is considered. The magnetization field in the absence of the uniform macro-scopic anisotropy is a conglomerate of the so-called stochastic domains (SDs) or magnetic blocks (MBs) with length $\delta_{S}[1-4]$.

Ferromagnetic crystallites forming a wire exhibit the random orientation of local easy magnetization axes (EMAs). The crystallites are so small that the inequality $a \ll \delta_{0}$ can be considered valid, where $a$ is the crystallite size and $\delta_{0}=\sqrt{A / K}$ is the domain wall size in a homogeneous material ( $A$ and $K$ are the exchange and anisotropy constants, respectively). Since the parameter $a$ is small, the coordinate dependence of the magnetization $\mathbf{m}(\mathbf{r})$ inside a crystallite can be considered weak. The total energy $E\left(\vartheta_{1} \ldots \vartheta_{N+1}, \phi_{1} \ldots \phi_{N+1}\right)$ of a magnet is represented by a function of magnetization direction angles at the grain boundaries, including polar angle $\vartheta$ and azimuth angle $\phi$. For the expression for energy $E$, we took into account the exchange energy

\footnotetext{
*aaivn@yandex.ru

†orlhome@rambler.ru

(c) Siberian Federal University. All rights reserved
} 
inside a crystallite and between crystallites, the anisotropy energy, the Zeeman energy, and the magnetostatic interaction energy between crystallites in the dipole approximation.

To calculate the effective anisotropy constant for a block, one can write the torque from the random anisotropy field of a crystallites ensemble contained in the SD and the effective anisotropy torque as:

$$
M_{\vartheta}=\frac{\partial}{\partial \vartheta} \sum_{n=1}^{N} v_{n} K_{n}\left(\mathbf{m}_{n} \mathbf{e}_{n}\right)^{2}, \quad M_{\vartheta_{e f}}=\frac{\partial}{\partial \vartheta} V K_{e f}\left(\mathbf{m e}_{e f}\right)^{2} .
$$

Here, $v_{n}$ and $K_{n}$ are the volume and local anisotropy constants for the $n^{\text {th }}$ crystallite respectively, $\mathbf{e}_{n}$ are the EMA direction orts, and $N$ is the number of crystallites in a SD, $K_{e f}$ and $\mathbf{e}_{e f}$ are the effective anisotropy constant and the effective anisotropy axis (EAA) direction vector of the block respectively, and $V=\sum v_{n}$ is the block volume. Expressions (1) were equalized to obtain $K_{e f}=\left[\frac{\left\langle K^{2}\right\rangle-\mu^{2}\langle K\rangle^{2}}{N}\left(\sigma_{v}^{2}+1\right)+\mu^{2}\langle K\rangle^{2}\right]^{\frac{1}{2}}$. Here, $\mu=\left\langle\cos \left(2\left(\alpha_{n}-\alpha_{m}\right)\right)\right\rangle, \alpha$ is the crystallite EMA polar angle, and $\sigma_{v}$ is the dimensionless crystallite volume dispersion.

To study the features of the distribution of the SD effective easy axes directions, one can return to Eq. (1). Using this equation, the expression for the effective direction of the anisotropy axis is obtained: $\sin \left(2 \alpha_{e f}\right)=\frac{K}{K_{e f}} \sum_{n=1}^{N} \sin \left(2 \alpha_{n}\right)=s_{0}$.

The density of distribution of the quantity $\sin \left(2 \alpha_{e f}\right)=s$ can be presented in the form $\rho(s)=\int_{-\alpha_{0}}^{\alpha_{0}} \ldots \int_{-\alpha_{0}}^{\alpha_{0}} \prod_{n=1}^{N} \rho\left(\alpha_{n}\right) \delta\left(s-s_{0}\right) d \alpha_{n}$. Here, $\rho\left(\alpha_{n}\right)$ is the density of distribution of the EMA polar angles. For simplicity, assume this function to be independent on the crystallite number and $\alpha_{0}$ to be a half of the polar angle of cone opening in the EMA distribution. Then multiply $\rho(s)$ by the exponential factor with fitting parameter $\beta$ and expansion in the Fourier integral [5]. After we make the inverse transform. The calculated $\rho\left(\alpha_{e f}\right)$ values are presented in Fig 1 in comparison with the Gaussian approximation of the calculated density $(\beta=0)$.

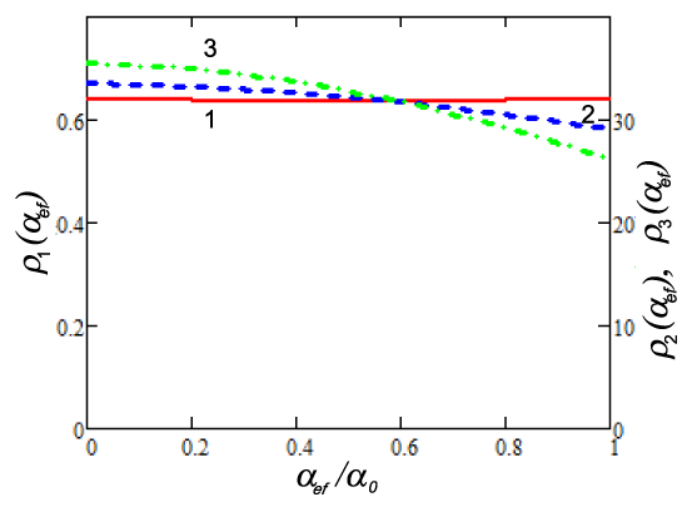

Fig. 1. Polar angles distribution of the effective anisotropy axis of a stochastic domain. Plot 1 and Plot 2 show the uniform distribution of local axes in a cone from $-\pi / 2$ to $+\pi / 2$ and in a cone from $-\pi / 100$ to $-\pi / 100$ respectively; Plot 3 shows the Gaussian approximation for a cone from $-\pi / 100$ to $-\pi / 100$

With appearance of the magnetostatic interaction SDs become invisible. Classical domains and domain walls appear. Meanwhile, the magnetization self-organization is observed in nanowires in the presence of the uniform macroscopic anisotropy induced by magnetostatics. 
Stochastic domains are analogous to the normal modes of bound oscillators, which can be excited or not, but exist as a structural unit.

We apply an external magnetic field in the direction opposite to the average magnetization. The applied field increases deviations of the magnetization from the $z$ axis direction. The beginning of this process is illustrated in Fig. 2a. When the external field attains a critical value

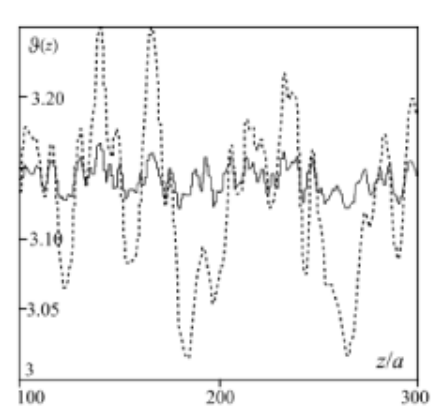

a)

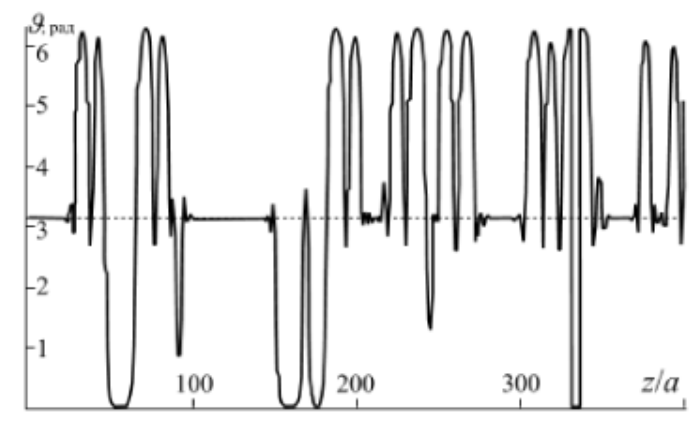

b)

Fig. 2. Enhancement of magnetization fluctuations with the increase in the external magnetic field $h=H M_{S} / K$. The solid line corresponds to $h=0$ and the dashed line corresponds to $h=0.05$ (figure a). Domain structure formed at attaining the critical field (figure b)

$H_{n u c l} \approx 0.16 \mu_{0} M_{S}$, the magnetization of separate nuclei rotates drastically, which results in the emergence of 180- or 360-degree domain walls [6]. Fig. 2b illustrates the end of this process. The obtained domains are located in the places where SDs would be located if the induced magnetostatic anisotropy is absent.

Spectral study of the magnetization distribution function allows considering the structure in more detail without switching the sample magnetization. Consider the spectral density of the spatial distribution of the polar angle $\vartheta(z)$. The effects masking the self-organization (external field, texture in the EMA directions, magnetostatics, etc.), are not reflected in the spectral density. The long-wavelength region makes the main contribution to the spectral density.

In this study, the nanowire magnetization switching was simulated in order to investigate the pinning force spectrum. As the magnetic field applied along the $z$ axis was increased, the total SD energy was detected and its derivative yielded the force of interaction between the wall and inhomogeneities. Figure 3 presents the result of the spectral analysis of the force relief with the same cross section and parameter $b=a / \delta_{0}=0.1$, but different ratios $\mu_{0} M_{S}^{2} / K$. The maximum corresponding to the large $k$ values is determined by the magnetization ripples upon tuning to the local anisotropy of separate crystallites. The wavelength of this ripples is about $b$. The other maximum is, in our opinion, complex and contains peaks responsible for the domain wall width $\delta_{W}$ and SD size (in this case, their characteristic sizes are comparable, i.e., the average wavelengths coincide). The figure shows that with decreasing of $M_{S}$, the maximum creeps and the density peak responsible for the increasing domain wall width becomes pronounced. In this case, the peak responsible for the SD is nearly invariable. Thus, the force relief has at least three pronounced harmonics: a) SD size (long-wavelength mode); b) domain wall (long-wavelength mode); c) crystallite size (short-wavelength mode). The theoretical numerical estimation of $\delta_{W}$ is in satisfactory accordance with the simulation results shown in Fig. 3.

We reported the results of computer simulation of the properties of magnetization and relief pinning a domain wall in $1 \mathrm{D}$ inhomogeneous ferromagnets. The dependence of the harmonic 
wavelength responsible for the stochastic domain on the linear crystallite size coincides with the theoretical estimates.
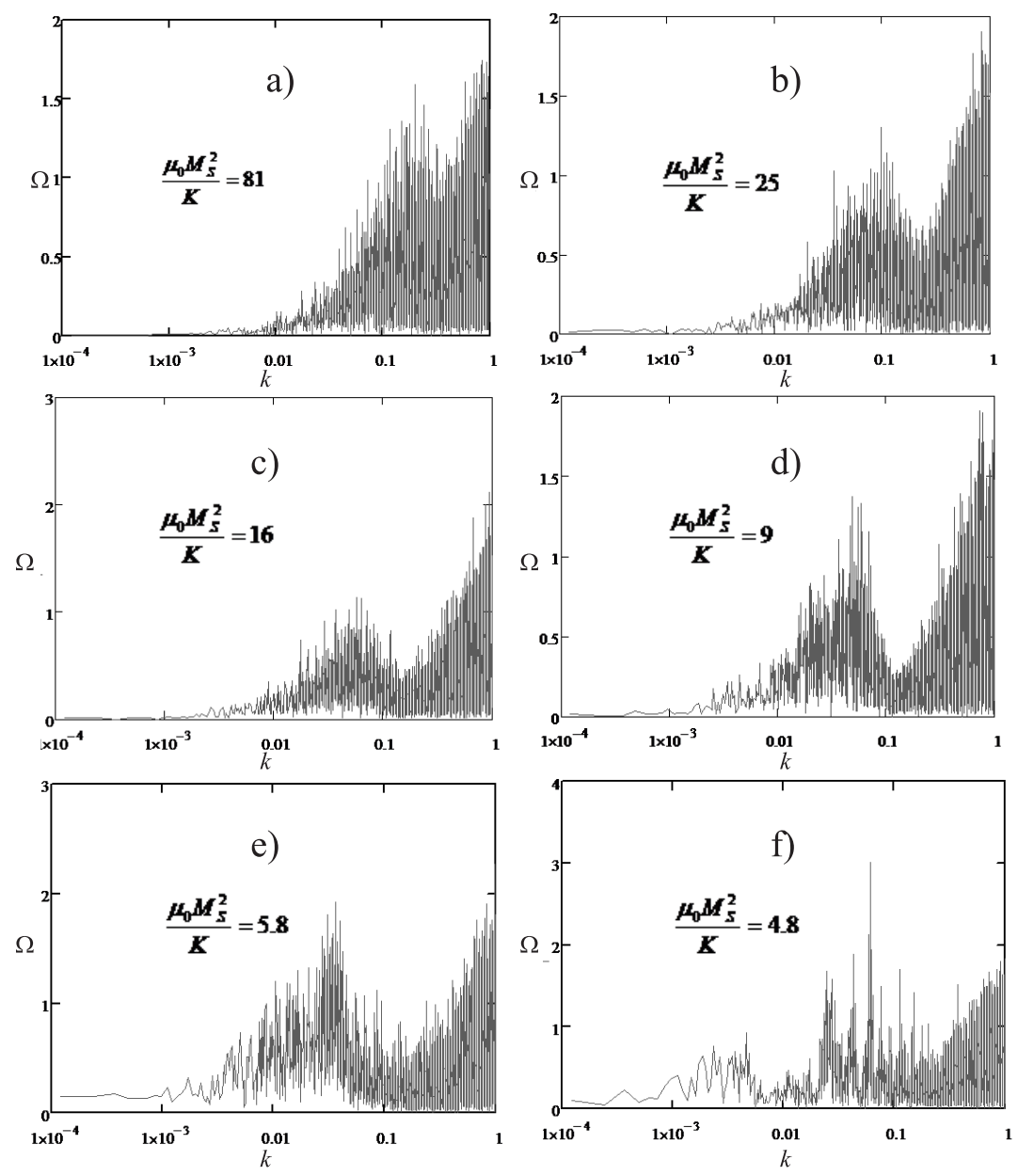

Fig. 3. Spectral density $\Omega(k)$ of the force relief for samples with different $M_{S}$ values. The EMA directions are distributed randomly and uniformly over a sphere. Here, $k \approx 1 / \lambda$, where $\lambda$ is measured in units of $a$

This study was supported by RFBR, project no. 14-02-00238-a.

\section{References}

[1] V.A.Ignatchenko, The magnetic structure of magnetic thin films and FMR, JETP, 27(1968), 303-311.

[2] Y.Imry, S.-K.Ma, Random-Field Instability of the Ordered State of Continuous Symmetry, Phys. Rev. Lett., 35(1975), 1399.

[3] E.M.Chudnovsky, W.M.Saslov, R.A.Serota, Ordering in ferromagnets with random anisotropy, Phys. Rev. B, 33(1986), 251-261. 
[4] A.A.Ivanov, V.A.Orlov, G.O.Patrushev, Orientational and Spatial Disorder in the Anisotropy Field, The Physics of Metals and Metallography, 84(1997), 125-129.

[5] I.V.Lobov, Method of calculating the critical breakthrough of dislocations through a grid of randomly positioned dissimilar point obstacles, The Physics of Metals and Metallography, 61(1986), 817-819.

[6] A.A.Ivanov, V.A.Orlov, Scenarios of Magnetization Reversal of Thin Nanowires, Physics of the Solid State, $\mathbf{5 7}(2015), 2204-2212$.

\title{
Об иерархии характерных длин намагниченности нанопроволок
}

\author{
Анатолий А. Иванов \\ Институт цветных металлов и материаловедения \\ Сибирский федеральный университет \\ Свободный, 79, Красноярск, 660041 \\ Россия \\ Виталий А. Орлов \\ Институт инженерной физики и радиоэлектроники \\ Сибирский федеральный университет \\ Свободный, 79, Красноярск, 660041 \\ Красноярский научный центр СО РАН \\ Академгородок 50, Красноярск, 660036 \\ Россия
}

\begin{abstract}
В компъютерном моделировании намагниченности в поликристаллической ферромагнитной нанопроволоке продемонстрировано возникновение характерного пространственного масштаба $ө$ распределении намагниченности, не связанной с размером доменной стенки или размером кристаллита. Это размер стохастического домена. Показано, что данная длина не только проявляется при анализе распределения намагниченности, но и содержится в спектралъной плотности силы, закрепляющей доменную стенку на неоднородностях кристаллографической анизотропии. Аналитически вычислены параметры стохастического домена: константа и распределение направлений осей эффективной анизотропии.
\end{abstract}

Ключевые слова: доменная стенка, нанопроволока, магнитные неоднородности. 